\title{
SYNTHESIS OF POLYHYDROXYBUTYRATE NANOPARTICLES USING SURFACTANT (SPAN20) FOR HYDROPHOBIC DRUG DELIVERY
}

\author{
P. Senthilkumar ${ }^{1}$, S. S. Dawn ${ }^{2}$, C. Saipriya ${ }^{3}$, and Antony V. Samrot ${ }^{3 *}$ \\ ${ }^{1}$ Department of Chemical Engineering, \\ Sathyabama Institute of Science and Technology, Chennai, India \\ ${ }^{2}$ Center for Waste Management, \\ Sathyabama Institute of Science and Technology, Chennai, India \\ ${ }^{3}$ Department of Biotechnology, Sathyabama Institute of Science and Technology, Chennai, India \\ *E-mail: antonysamrot@gmail.com
}

\begin{abstract}
Biopolymers like polyhydroxybutyrate (PHB) are biocompatible and biodegradable, it forms nanoparticle when appropriate solvent systems are employed. Thus, they fulfill the major requirement as a drug carrier. In this study, surfactant (Span20) influenced PHB nanoparticles were prepared by nanoprecipitation method with different solvent systems i.e. Chloroform:DMSO (CD), Chloroform: Water (CW), Ethylacetate: DMSO (ED) and Ethylacetate:Water (EW). The nanoparticles were also loaded with a hydrophobic drug - curcumin. Further, the produced nanoparticles were characterized and utilized for in-vitro drug release studies. The nanoparticles were below 300nm in size and these nanoparticles were found to release the drug for longer duration i.e. more than 110 minutes. From the controlled release studies carried out against Bacillus subtilis, it was found that the nanoparticles released the encapsulated drug (Curcumin) efficiently, when acetic acid was used as the solvent system.
\end{abstract}

Keywords: Biopolymer, Nanoparticles, PHB, Surfactant.

(C) RASĀYAN. All rights reserved

\section{INTRODUCTION}

Nanotechnology deals with the formation and utilization of particles from a broad range of sources and are used in a variety of fields, naming a few; agriculture ${ }^{1}$, gene therapy ${ }^{2}$, art conservation ${ }^{3}$, theranostics ${ }^{4,5}$ and drug delivery ${ }^{6,7}$. Drug delivery and nanotechnology joined hands for novel reasons such as increased stability of the drug, higher surface area, decreased drug resistance and enhanced rate of dissolution, solubility, etc ${ }^{8}$. Majorly, the half-life of the poorly-water soluble drugs in systemic circulation is prolonged when it is encapsulated in nanoparticles ${ }^{9}$. It is also to be noted that, more than 20 nanoparticles are already in clinical use with respect to therapeutics, indicating the ability of these particles to enhance the value of drugs ${ }^{10}$. Though they prove to have such inestimable applications, they are still not accepted widely as they are toxic to some extent. ${ }^{11-14}$ The nanoparticles acquire size depend on properties which also implies an effect on its toxic nature. A wide range of metal nanoparticles also shows some toxic effect to live cells ${ }^{15}$. To overcome this drawback, biopolymers are used as the base materials ${ }^{16}$. Biopolymers are known for their non-toxic nature, biodegradability and biocompatibility ${ }^{17}$. Polyhydroxyalkanoates (PHA) is one of the many biopolymers and is a linear chain of various ester groups that are produced in bacteria during physiologically stressful conditions as a carbon source and energy reserve. They exhibit good physiochemical properties that are exploited for many biomedical applications. ${ }^{18-20}$ Polyhydroxybutyrate (PHB) is the first found, four carbon chained homopolymer under the category ${ }^{21}$ and it is universally known as an alternative for plastics ${ }^{18}$. PHB is being used as implantation material, biofuel etc. ${ }^{22,23}$ Nanoparticles were also prepared and researched widely from PHB with major application in drug delivery. ${ }^{21}$

Rasayan J. Chem., 11(4), 1686-1695(2018)

http://dx.doi.org/10.31788/RJC.2018.1144053

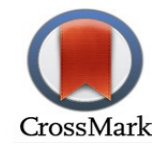


PHB nanoparticles loaded with rifampicin have been used in wound dressing with cotton gauze ${ }^{24}$. These PHB based nanoparticles are commonly produced using various methods such as salting out, solvent evaporation, supercritical fluid technology, dialysis, nanoprecipitation, emulsion, etc ${ }^{25}$. PHB nanoparticles are efficiently prepared using surfactants ${ }^{26}$ and are also used for drug delivery ${ }^{27}$. Utilizing surfactants like pluronic acid enhances the drug encapsulation and also has influence in size formation ${ }^{28}$. In emulsion/solvent evaporation technique, PHA is dissolved in an organic solvent (preferably chloroform/DMSO) and then emulsified in water having surfactants; the solution is then evaporated to produce micro/nanoparticles ${ }^{29}$. Parameters like the choice of solvent and surfactant concentration are crucial in size formation ${ }^{30,31}$ as this surfactant reduces the droplet coagulation and form stable nanometric particles $^{32}$. Surfactants like SDS, Tween, pluronic acid and polyvinyl chloride are commonly used surfactants in the production of PHB based nanoparticles ${ }^{28,30}$. Curcumin is a well-known drug which exhibits versatile bioactivities like antioxidant activity, anticancer activity, antibacterial activity, antiinflammatory activity etc ${ }^{33,34}$. But, these exemplary properties are blinded by its poor bioavailability and solubility that are due to factors such as administration route, elimination and rapid metabolism of curcumin in the system ${ }^{35}$. Having known the importance of surfactants in the production of PHB nanoparticles especially in size reduction and drug encapsulation, we wanted to utilize Span 20 as surfactants rather using the common surfactants like Tween and SDS. In this study, various solvent systems were utilized, where PHB was dissolved in non-polar solvents (either chloroform or ethyl acetate) and this solution was dropped into anti-solvent (either water or DMSO) in presence of Span 20. Curcumin was loaded into PHB nanoparticles and the nanoparticles were characterized using FTIR, SEM and AFM. The efficiency of the nanoparticle to encapsulate and release the loaded drug was also studied.

\section{Materials Required}

\section{EXPERIMENTAL}

Polyhydroxybutyrate (PHB) (derived from microbial fermentation) (Sigma-Aldrich, India), Chloroform (Qualigens, India), Ethylacetate (Qualigens, India), DMSO (Qualigens, India), Curcumin (SRL, India), Span20 (HiMedia, India). Distilled water was used all through the experiment. All the chemicals were either analytical grade or extra pure.

\section{Synthesis of PHB Nanoparticles}

PHB nanoparticles were synthesized by a slight modification of the nanoprecipitation method explained by Shakeri et $\mathrm{al}^{36}$ wherein, $0.05 \%$ PHB was dissolved in the respective solvent (chloroform/ethyl acetate) and heated. Later the above mixture was suspended into the anti-solvent (water/DMSO) under magnetic stirring, subsequently $0.1 \%$ Span 20 was added drop-wise. The precipitates so formed were collected and lyophilized for further usage. To prepare curcumin loaded nanoparticles, $2.5 \mathrm{mg}$ of curcumin was initially added to the non-polar solvents, then it was performed to form nanoparticle as described earlier.

\section{Characterization of PHB Nanoparticles}

\section{Fourier Transform Infrared Spectroscopy (FTIR)}

Various functional groups present in the prepared PHB nanoparticle was identified using the different modes of vibrations ${ }^{37} .1$ to $2 \%$ of PHB nanoparticles was added to $\mathrm{KBr}$ solution was heated and ground to obtain a homogenous mixture. This mixture was plated into $\mathrm{KBr}$ discs using standard methods ${ }^{38}$. They were then encountered with a spectrum ranging from 4000 to $500 \mathrm{~cm}^{-1}$ IR Affinity-1s (Shimadzu, Japan) in transmission mode. A graph was plotted against wavelength and transmission rate.

\section{Scanning Electron Microscopy (SEM)}

In order to measure the size and visualize the distribution of the particles, the PHB nanoparticles were diluted to a concentration of $1 \mathrm{mg} / \mathrm{ml}$ by dispersing them into deionized water and a drop of it was mounted on a glass slide which was embedded on stubs and dried at room temperature. Later they were sputtered with gold and viewed under SEM (SEI and BSI).

\section{Atomic Force Microscopy}

A thin layer of nanoparticle was mounted onto a glass slide and viewed in atomic force microscopy (Bruker, Germany) by which the surface topography of the nanoparticles was visualized. 


\section{Drug Encapsulation Efficiency}

Immediately after producing the curcumin loaded nanoparticles, $1 \mathrm{ml}$ of the supernatant was aspirated after centrifugation at $5000 \mathrm{rpm}$. This was performed for every 10 minutes and checked for absorbance at $421 \mathrm{~nm}$ using UV visible spectrophotometer (Systronics), as $421 \mathrm{~nm}$ is the absorbance maxima of curcumin $^{39}$. A graph was plotted against time and absorbance to identify the efficiency of the nanoparticles to encapsulate the drug with respect to time.

\section{In Vitro Drug Release Kinetics}

The ability of the nanoparticle to release the encapsulated drug was checked using the dialysis method ${ }^{40}$. Dialysis membrane containing a suspension of nanoparticle in PBS (pH 7) in the ratio 0.5:1 was placed in acidic PBS solution ( $\mathrm{pH} \mathrm{3}$ ) at room temperature and every $10 \mathrm{~min}, 1 \mathrm{ml}$ of the external solution was collected up to $180 \mathrm{~min}$. They were then checked for the absorbance of curcumin by measuring the absorbance using UV visible spectrophotometer (Systronics) at a wavelength of $421 \mathrm{~nm}^{39}$. A graph against absorbance and time was plotted.

\section{In-Vitro Controlled Release Studies}

Controlled release study was performed using agar well diffusion method. In this study, two different solvents- PBS ( $\mathrm{pH} 7$ ) or acetic acid (1\%) were utilized to dissolve the nanoparticles. Nutrient agar plates were swabbed all over with Bacillus subtilis and wells were bored. Different concentrations (2, 4, 6, $8 \mu \mathrm{g} / \mathrm{ml}$ ) of nanoparticles dispersed in respective solvents were added to the wells ${ }^{41}$. Erythromycin was used as positive control and the respective solvent as a negative control. The plates were incubated for $24 \mathrm{~h}$ and the zone of inhibition was recorded.

\section{RESULTS AND DISCUSSION \\ Fourier Transform Infrared Spectroscopy (FTIR)}

Strong peaks at $1724-1760 \mathrm{~cm}^{-1}$ shows the presence of $\mathrm{C}=\mathrm{O}$ which is the characteristic of $\mathrm{PHB}$ and peaks

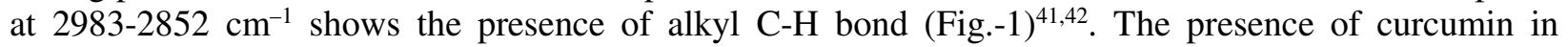
loaded samples (Fig.-1b, d, f, h) was confirmed by the presence of peaks at $3503-3436 \mathrm{~cm}^{-1}$ for the presence of $\mathrm{OH}$ bond whereas, $980-678 \mathrm{~cm}^{-1}$ was indicating the $=\mathrm{C}-\mathrm{H}$ bend. $1594-1432 \mathrm{~cm}^{-1}$ was showing the $\mathrm{C}-\mathrm{C}$ bond and 1051 to $1229 \mathrm{~cm}^{-1}$ was showing the presence of $\mathrm{C}-\mathrm{O}$ bond ${ }^{43}$. $\mathrm{C}-\mathrm{O}-\mathrm{H}$ bond of curcumin was found at $1375 \mathrm{~cm}^{-1}$ to $1351 \mathrm{~cm}^{-1}$. C-O of curcumin was found between $1194 \mathrm{~cm}^{-1}$ and $1184 \mathrm{~cm}^{-1}$ (Fig.-1b, d, f, h) ${ }^{44}$.

\section{Scanning Electron Microscopy (SEM)}

All the nanoparticles prepared in this study were spherical in shape. The unloaded nanoparticles prepared using Chloroform:DMSO was in size ranging from $104 \mathrm{~nm}$ to $400 \mathrm{~nm}$, where the loaded were between 200 and 600nm (Fig.-2a, b), the unloaded particles of Chloroform:water was ranging from $48 \mathrm{~nm}$ to 75 $\mathrm{nm}$, while it was loaded with drug, it increased the size to $350-700 \mathrm{~nm}$ (Fig.-2c, d). The drug loaded and unloaded particles prepared using Ethyl Acetate:DMSO had size around 157nm to 550nm (Fig.-2e, f) and the size of Ethyl Acetate:Water was $98 \mathrm{~nm}$ to $361 \mathrm{~nm}$ (Fig.-2g, h). The shape was uniformly spherical in the nanoparticles prepared using DMSO as anti-solvent. Drug-loaded nanoparticles formed using the water and ethyl acetate was found to be aggregated and non-uniform in shape. Span was found to produce a particle of smaller size than the other surfactant utilized preparations. In our earlier report, we have produced polyhydroxyalkanoate nanoparticles without any surfactant and the minimal size we could achieve was around $290 \mathrm{~nm}^{45}$. Thus it is proving that Span 20 was having influence in size reduction, even in most cases it was producing spherical shaped nanoparticles. There are reports saying that surfactant influences nanoparticles ${ }^{33}$, where $250-710 \mathrm{~nm}$ and below $300 \mathrm{~nm}$ sized PHB nanoparticle were produced using SDS ${ }^{45}$ and PVA as surfactant ${ }^{45}$, where Sasikumar et $\mathrm{al}^{47}$ have achieved to produce $100 \mathrm{~nm}$ sized PHB nanoparticles with TWEEN 80 by nanoprecipitation method. Increasing concentration of surfactant (TWEEN 80) was found to decrease the size of PHB nanoparticles ${ }^{36}$. Drug-loaded nanoparticle was looking bigger than the unloaded one. Increasing the concentration of organic phase has been reported to influence in the reduction of the size of PHB based nanoparticles ${ }^{48}$. 


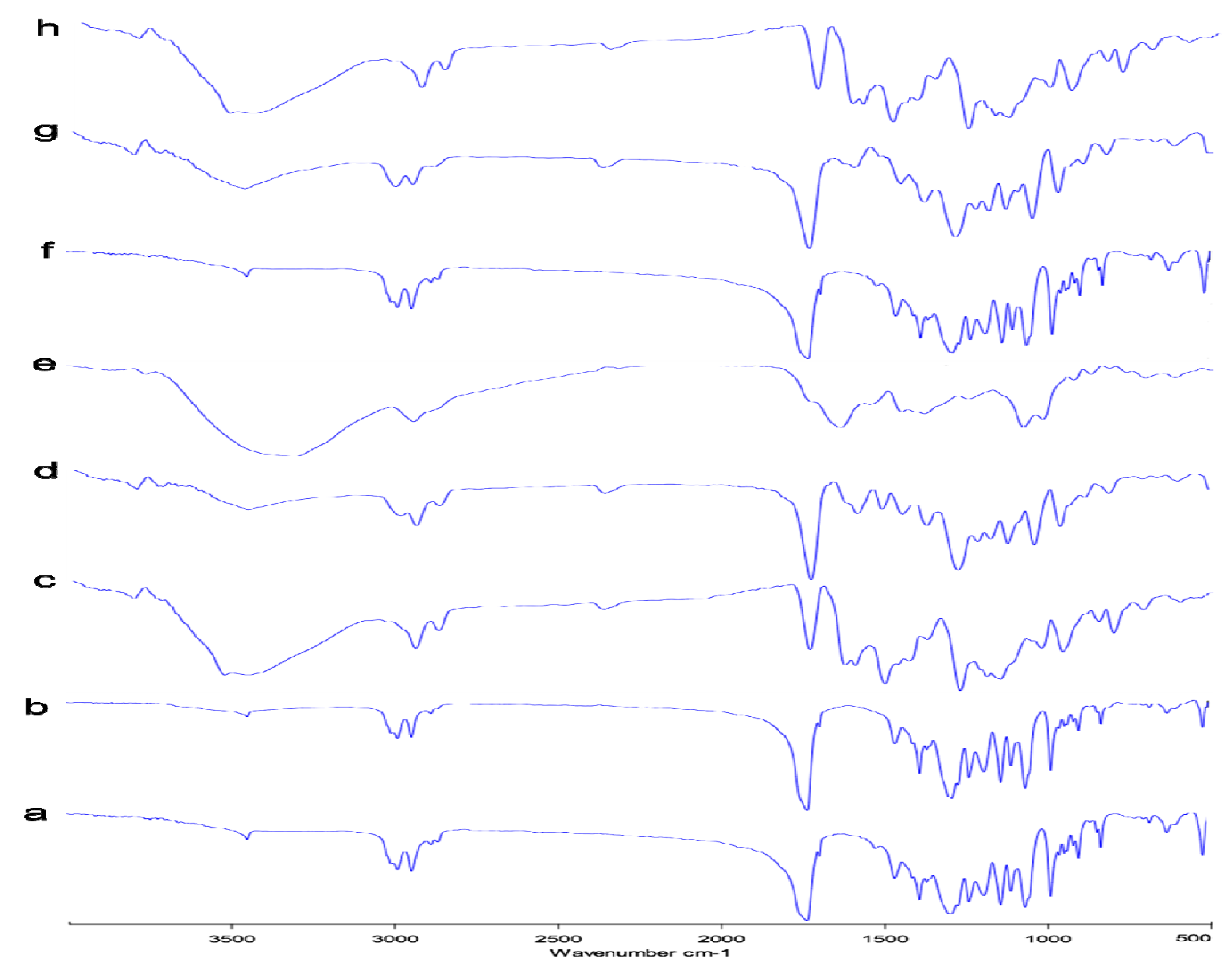

Fig.-1: FTIR Analysis: Nanoparticles prepared using (a) Chloroform and DMSO, (b) Curcumin, Chloroform and DMSO, (c) Chloroform and Water, (d) Curcumin, Chloroform and water, (e) Ethyl acetate and DMSO, (f) Curcumin, Ethyl acetate and DMSO, (g) Ethyl acetate and Water, (h) Curcumin, Ethyl acetate and Water

\section{Atomic Force Microscopy (AFM)}

From AFM analysis, all the samples were found to form smooth, spherical shaped and aggregated nanoparticles. Smallest particles of size ranging between 48 and $68 \mathrm{~nm}$ was produced while ChloroformDMSO was used (Fig.-3a, b); $41 \mathrm{~nm}$ and $96 \mathrm{~nm}$ for nanoparticles prepared using Chloroform-Water (Fig.3c, d); 24nm and 53nm for Ethyl Acetate-DMSO as solvent system (Fig.-3e, f) and 60 to 96nm for Ethyl Acetate - Water as solvent system (Fig.-3g, h). Surfactants like tween and SDS were forming bigger sized micro/nanoparticles ${ }^{36,45-47}$. Size of the particles was reported as decreasing while the surfactant concentration was increasing ${ }^{36}$. Kilicay et $\mathrm{al}^{49}$ found $\mathrm{PHB}$ based nanoparticles produced by transesterification process to be a size between 230 and $235 \mathrm{~nm}$ by AFM analysis.

\section{Drug Encapsulation Efficiency}

After characterization, the nanoparticles were utilized for curcumin encapsulation. The nanoparticles were found to encapsulate the curcumin in a constant fashion except for the nanoparticles formed using chloroform-DMSO (Fig.-4). Encapsulation was found to be increasing as time duration increased. Nanoparticles prepared using Chloroform - Water, encapsulated drug efficiently and better. Surfactants were reported to enhance the drug loading efficiency ${ }^{30,31}$. In a study, it was found that the encapsulation of curcumin into PHA nanoparticles was slower when surfactant was not used ${ }^{44}$. Shakeriet $\mathrm{al}^{36}$ have loaded lipophilic carvocrol into PHB based nanoparticles and the loading efficiency was found to be $21 \%$. Even 
RASĀYAN J. Chem.

Vol. 11 | No. 4 |1686 - 1695| October - December | 2018

in our earlier study, we found polyhydroxyalkanoate based nanoparticles to encapsulate curcumin efficiently ${ }^{44}$.
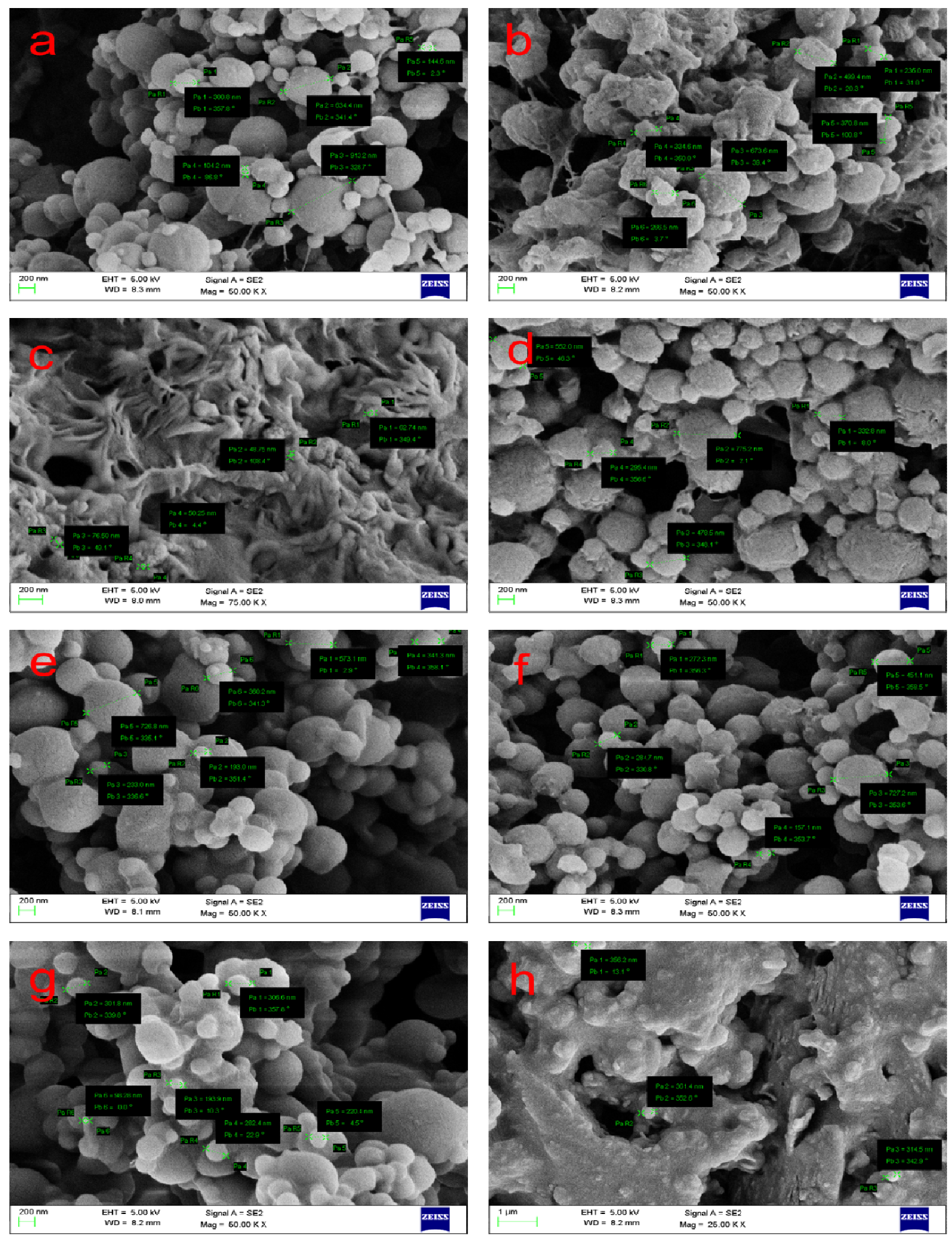

Fig.-2: SEM Analysis: Nanoparticles prepared using (a) Chloroform and DMSO, (b) Loaded, Chloroform and DMSO, (c) Chloroform and Water, (d) Loaded, Chloroform and water, (e) Ethyl acetate and DMSO,(f) Loaded, Ethyl acetate and DMSO, (g) Ethyl acetate and Water, (h) Loaded, Ethyl acetate and Water 
RASĀYAN J. Chem.

Vol. 11 | No. 4 |1686 - 1695| October - December | 2018
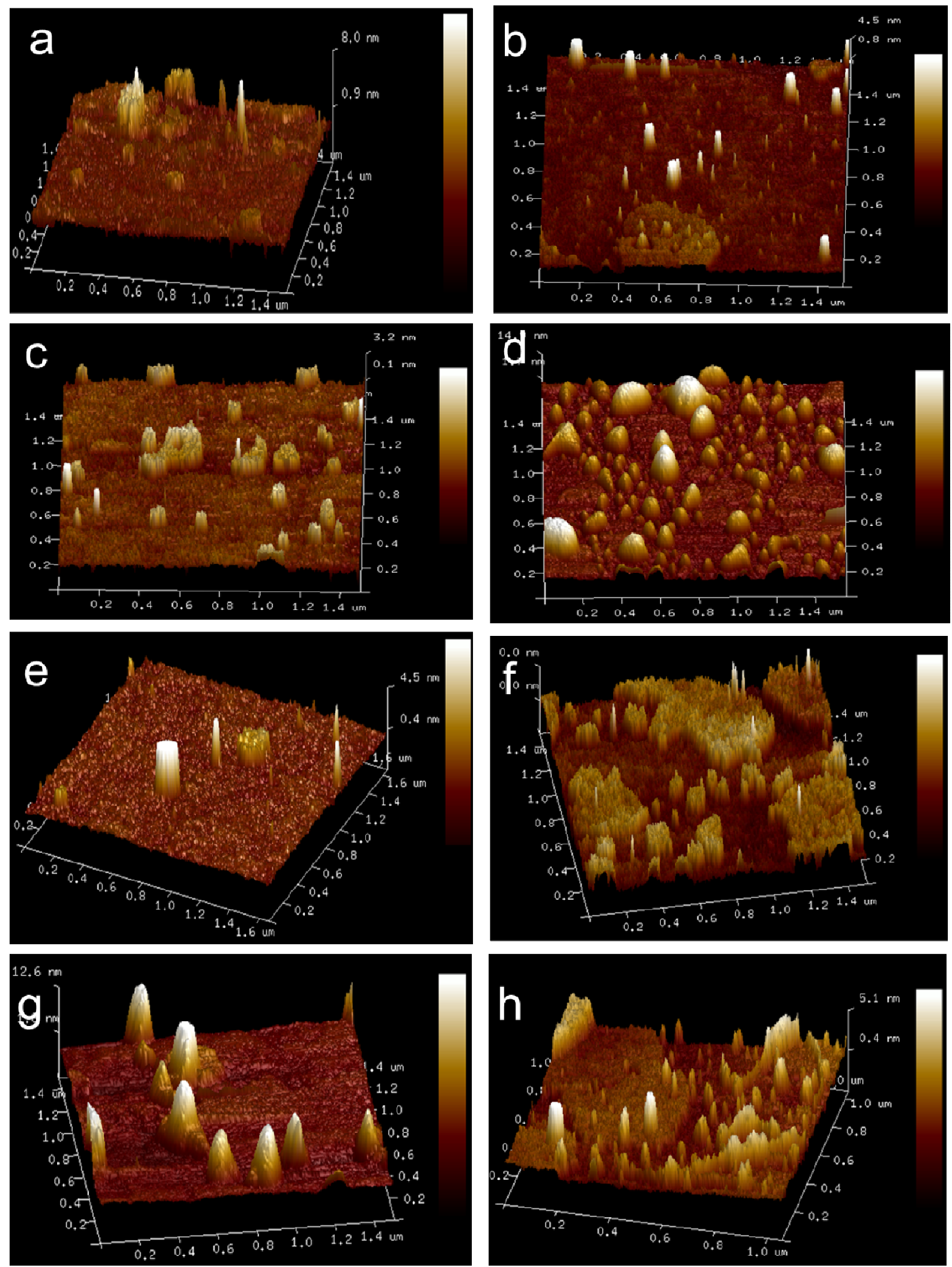

Fig.-3: AFM analysis Nanoparticles prepared using (a) Chloroform and DMSO, (b) Loaded, Chloroform and DMSO, (c) Chloroform and Water, (d) Loaded, Chloroform and water, (e) Ethyl acetate and DMSO, (f) Loaded, Ethyl acetate and DMSO, (g) Ethyl acetate and Water, (h) Loaded, Ethyl acetate and Water 


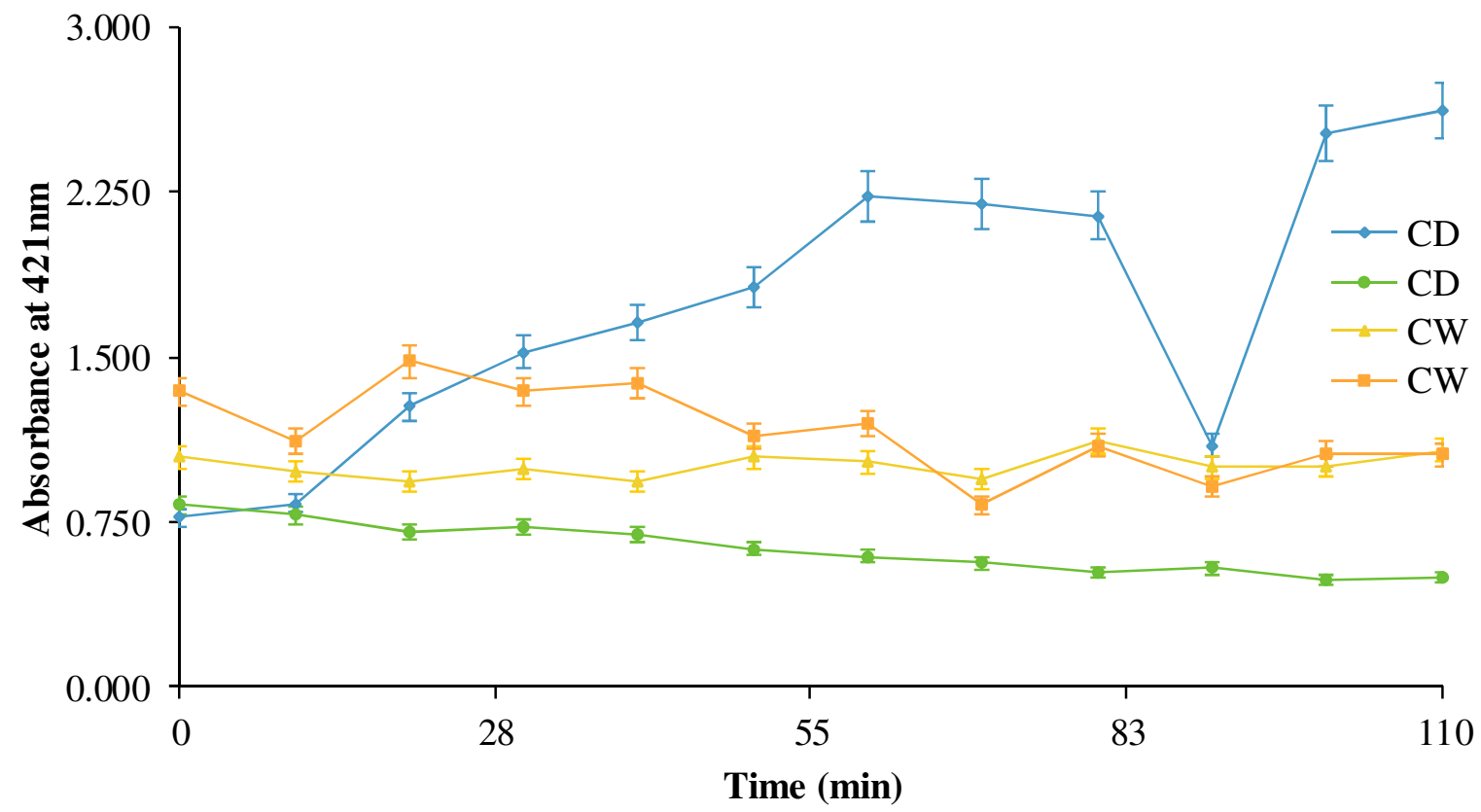

Fig.-4: Drug Encapsulation Efficiency Studies.

CD- Chloroform:DMSO, CW - Chloroform:Water, ED - Ethylacetate:DMSO, EW - Ethylacetate:Water

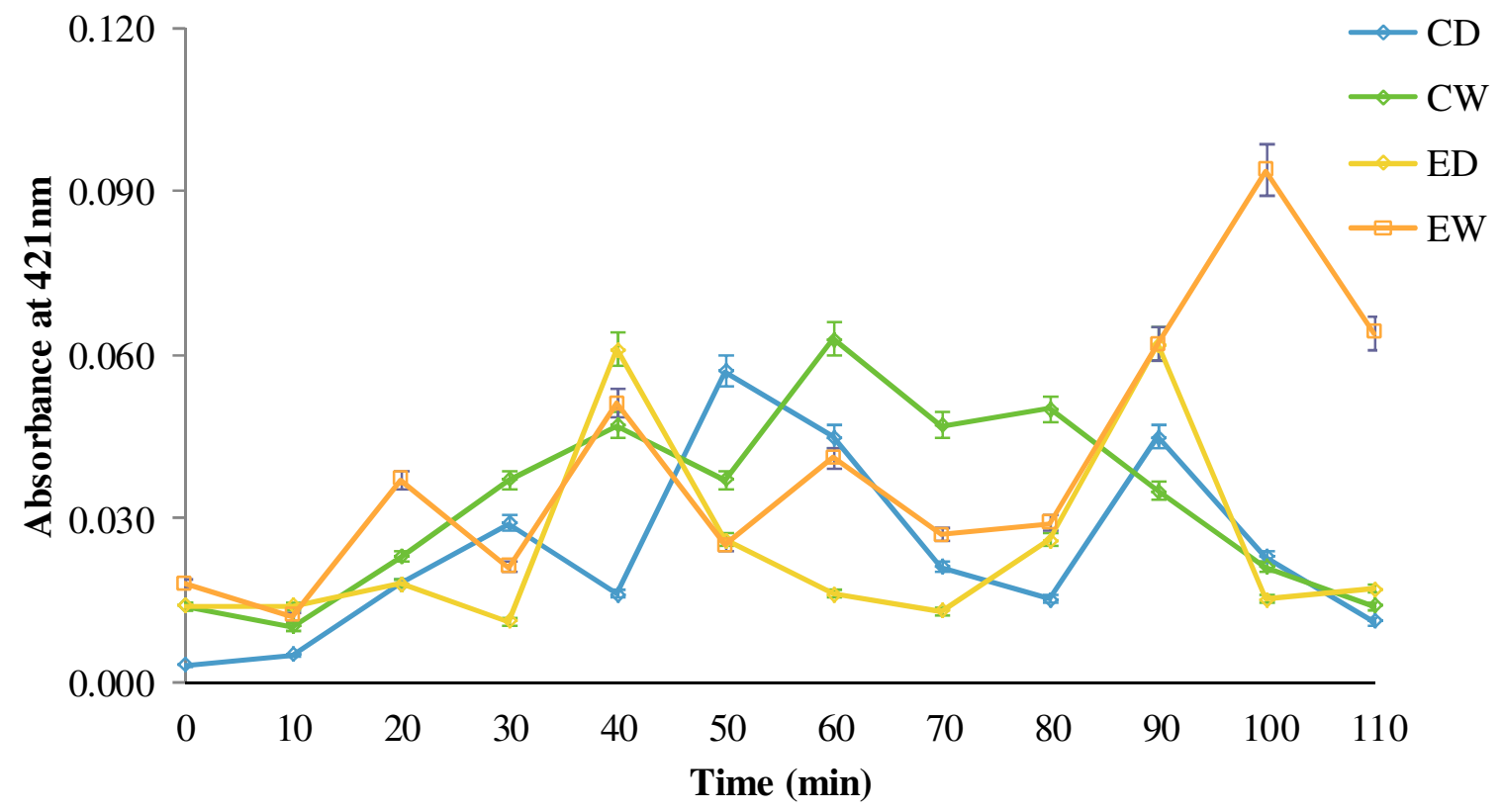

Fig.-5: In Vitro Drug Release Kinetics of PHB Nanoparticles, CD- Chloroform:DMSO, CW - Chloroform:Water, ED - Ethylacetate:DMSO, EW - Ethylacetate:Water

\section{In Vitro Drug Release Kinetics}

Nanoparticles produced using ethyl acetate: DMSO was found to release the drug faster i.e. in the $70^{\text {th }}$ min, where the other particles were releasing for longer time i.e. more than $110 \mathrm{~min}$ (Fig.-5). The drugloaded PHB nanoparticle was tended to release drug at $\mathrm{pH} 3$; even in our previous study ${ }^{44}$ we found the polyhydroxyalkanoate based nanoparticles to release curcumin at $\mathrm{pH} 3$ only. These nanoparticles tend to react with the acidic environment and disperse the loaded drug. Nachiyar et al ${ }^{46}$ reported that PHB 
nanoparticles produced using PVA as a surfactant to release levofloxacin for $24 \mathrm{~h}$. Sasikumar et $\mathrm{al}^{47}$ found PHB nanoparticles produced using TWEEN 80 as a surfactant to release doxorubicin for more than $72 \mathrm{~h}$.

Table-1: Anti-Bacterial Activity of PHB Nanoparticles against Bacillus subtilis

\begin{tabular}{c|c|c|c|c|c|c|c}
\hline Solvent System & +ve Control & +ve Control & - ve Control & $2 \mu \mathrm{g}$ & $4 \mu \mathrm{g}$ & $6 \mu \mathrm{g}$ & $8 \mu \mathrm{g}$ \\
\hline \multirow{4}{*}{ PBS } & Chloroform-DMSO & 2.6 & - & - & - & - & - \\
\cline { 2 - 8 } & Chloroform-Water & 2.6 & - & - & - & - & - \\
\cline { 2 - 8 } & Ethyl acetate-DMSO & 2.6 & - & - & - & - & - \\
\cline { 2 - 8 } & Ethyl acetate-water & 2.6 & - & - & - & - & - \\
\hline \multirow{4}{*}{ Acetic acid } & Chloroform-DMSO & 2.6 & - & - & - & 0.5 & 0.7 \\
\cline { 2 - 8 } & Chloroform-Water & 2.6 & - & - & - & - & 0.7 \\
\cline { 2 - 8 } & Ethyl acetate-DMSO & 2.6 & - & - & - & 0.5 & 0.7 \\
\cline { 2 - 8 } & Ethyl acetate-water & 2.6 & - & - & - & 0.5 & 0.7 \\
\hline
\end{tabular}

\section{In-Vitro Controlled release Studies}

When the nanoparticles were dissolved in PBS, they did not show any zone which is in accordance with the earlier reports. When acetic acid was used, there was a slight increase in the activity (Table-1). The increase in the activity might be due to the breakdown of the outer PHB by the non-polar nature of acetic acid which would have caused the release of the encapsulated drug ${ }^{42}$. The effect could have also been due to the change in $\mathrm{pH}$ which is seen evidently from the drug release kinetics data (Fig.-5).

\section{CONCLUSION}

In this study, commercially available PHB was utilized for nanoparticle synthesis with different solvent system i.e. chloroform:DMSO, chloroform:water, ethyl acetate:DMSO and ethyl acetate:water and span20 as a surfactant and also utilized for loading hydrophobic drug - curcumin. Spherically shaped nanoparticles of size ranging from 40 to $100 \mathrm{~nm}$ were produced using the surfactant Span 20, which was confirmed by SEM and AFM analysis. Span 20 has influence in the drug encapsulation. Further, it was utilized for drug release studies, where it was released for more than 110 minutes. When acetic acid was used as a solvent, the nanoparticles released the drug efficiently which was confirmed by drug release kinetics and in-vitro controlled release study showing that acetic acid has an effect on the outer PHB nanoparticle which has led to the release of the encapsulated drug.

\section{REFERENCES}

1. M. Rai and A. Ingle, Applied Microbiology and Biotechnology, 94(2), 287(2012), DOI: 10.1007/s00253-012-3969-4.

2. P. Gopinath, S.K. Gogoi, A. Chattopadhyay and S.S. Ghosh, Nanotechnology, 19(7), 075104(2008), DOI:10.1088/0957-4484/19/7/075104.

3. M. Ioannides, D. Fritsch, J. Leissner, R. Davies, F. Remondino and R. Caffo, In Proceedings of 4th International Conference, EuroMed 2012, Lemessos, Cyprus, 7616, (2012), DOI:10.1007/978-3-64234234-9.

4. A.J. Cole, V.C. Yang and A.E. David, Trends in Biotechnology, 29(7), 323(2011), DOI: 10.1016/j.tibtech.2011.03.001.

5. C. Justin, S.A. Philip, A.V.Samrot, Applied Nanoscience, 7(7), 463 (2017), DOI: 10.1007/s13204017-0583-x.

6. O.C.Farokhzad and R. Langer, ACS Nano, 3(1): 16 (2009), DOI:10.1021/nn900002m.

7. A.V.Samrot, S.Padmanaban, R.K. Bhattacharya andA.A.Annamalai, Separation Technologies in Chemical, Biochemical, Petroleum and Environmental Engineering, 46(2016).

8. S. Bhatia, Natural Polymer Drug Delivery Systems, Springer International Publishing Switzerland, (2016), DOI:10.1007/978-3-319-41129-3.

9. S. Mazumder, A.K.Dewangan, and N.Pavurala, Asian Journal of Pharmaceutical Sciences, 12(6), 532 (2017), DOI:10.1016/j.ajps.2017.07.002. 
RASĀYAN J. Chem.

Vol. 11 | No. 4 |1686 - 1695| October - December | 2018

10. L. Zhang, F.X.Gu, J.M. Chan, A.Z. Wang, R.S. Langer and O.C. Farokhzad, Clinical Pharmacology \& Therapeutics, 83(5), 761 (2008), DOI:10.1038/sj.clpt.6100400.

11. A.V. Samrot, C. Justin, S. Padmanaban and U. Burman, Applied Nanoscience, 7(1-2), 17 (2017), DOI: $10.1007 / \mathrm{s} 13204-016-0542-\mathrm{y}$.

12. A .H. Panhwar, M. Tuzen, B. Hazer and T.G.Kazi, Talanta, 184, 115 (2018), DOI:10.1016/j.talanta.2018.03.004.

13. T.A. Saleh, M. Tuzen, A. Sarı, Journal of Environmental Management, 211, 323 (2018), DOI: 10.1016/j.jenvman.2018.01.050.

14. M. Tuzen,S. Sahiner and B. Hazer, Food Chemistry; 210, 115 (2016), DOI: 10.1016/j.foodchem.

15. S.M. Hussain, K.L. Hess, J.M. Gearhart, K.T. Geiss and J.J. Schlager, Toxicology in Vitro, 19(7), 975 (2005), DOI:10.1016/j.tiv.2005.06.034.

16. A.V. Samrot, U. Burman, S.A. Philip, N. Shobana andK. Chandrasekaran, Informatics in Medicine Unlocked, 10, 159 (2018), DOI:10.1016/j.imu.2017.12.010.

17. H. Honarkar and M. Barikani, Monatsheftefür Chemie-Chemical Monthly, 140, 1403 (2009), DOI:10.1007/s00706-009-0197-4.

18. Y.C. Xiong, Y.C.Yao, X.Y. Zhan and G.Q. Chen, Journal of Biomaterials Science, Polymer Edition, 21(1), 127 (2010), DOI:10.1163/156856209X410283.

19. A.V. Samrot, M. Bhakyalakshmi, K.L. Venkatraman, K. Sahiti, S.A. Philip andT. Jahnavi, Biosciences Biotechnology Research Asia, 12(3), 2133 (2015), DOI:10.13005/bbra/1883.

20. D. Akmal, P. D. Asiska, Q. A. Wangi, H. Rivai, and A. Agustien. Rasayan Journal of Chemistry, 8(3),389 (2015).

21. Z.A. Raza, S. Abid and I.M. Banat, International Biodeterioration\& Biodegradation, 126, 45 (2018), DOI:10.1016/j.ibiod.2017.10.001.

22. E. Grothe, M. Moo-young andY. Chisti,Enzyme and Microbial Technology, 25, 132 (1999), DOI: 10.1016/S0141-0229(99)00023-X.

23. G. Q. Chen, Chemical Society Reviews, 38(8), 2434 (2009), DOI:10.1039/b812677c.

24. M. Mekala and K. Suganya, African Journal of Pharmacy and Pharmacology, 12(11), 142 (2018), DOI:10.5897/AJPP2017.4865.

25. J.P. Rao and K.E. Geckeler, Progress in Polymer Science, 36, 887 (2011), DOI:10.1016/j.progpolymsci.2011.01.001.

26. V. Deepak, S.B. Pandian, K.Kalishwaralal and S. Gurunathan, Bioresource Technology, 100 (24), 6644(2009), DOI:10.1016/j.biortech.2009.06.057.

27. P.C.Reis, R.J. Neufeld, A.J. Ribeiro and F. Veiga, In Nanomedicine in Cancer,2(1), 8 (2006), DOI: 10.1016/j.nano.2005.12.003.

28. C. Errico, C. Bartoli, F. Chiellini andE. Chiellini, Journal of Biomedicine and Biotechnology, 571702 (2009), DOI:10.1155/2009/571702.

29. J.K. Rho, M.H. Choi, M. Gutierrez, B. Tian, T. Yoo, J. E. Baek, M. Shah, and S.C. Yoon, Journal of Applied Polymer Science,131, 41074 (2014), DOI:10.1002/app.41074.

30. J.L. Maia, M.H.A. Santana, M.I.Ré, Brazilian Journal of Chemical Engineering, 21(1), 1(2004), DOI: $10.1590 / \mathrm{S} 0104-66322004000100002$.

31. A. Musyanovych, J. Schmitz-Wienke, V. Mailänder, P. Walther, and K. Landfester, Macromolecular Biosciences,8(2), 127 (2008), DOI:10.1002/mabi.200700241.

32. J.W. Vanderhoff, M.S. El-Aasser and J.D. Hoffman, US Patent 4,070,323(1978).

33. B.B. Aggarwal, Y.J.Surh and S. Shishodia, The Molecular Targets and Therapeutic Uses of Curcumin in Health and Disease, In: Advances in Experimental Medicine and Biology, Springer Science \& Business Media, 2007, DOI: 10.1007/978-0-387-46401-5.

34. B. Selvakumar, and R. Venkataraman. Rasayan Journal of Chemistry, 3(2), 260(2010).

35. P. Anand, A.B. Kunnumakkara, R.A. Newman and B.B. Aggarwal, Molecular pharmaceutics,4(6), 807 (2007), DOI:10.1021/mp700113r. 
36. F. Shakeri, S. Shakeri and M. Hojjatoleslami, Journal of Food Science, 79(4), N697 (2014), DOI: $10.1111 / 1750-3841.12406$.

37. C. Dipankar and S.Murugan, Colloids and Surfaces B: Biointerfaces, 98, 112 (2012), DOI:10.1016/j.colsurfb.2012.04.006.

38. G. Dent, Internet Journal of Vibrational Spectroscopy, 1, 1(1996).

39. K. Hazra, R. Kumar, B.K. Sarkar, Y. A. Chowdary, M. Devgan and M. Ramaiah, International Journal of Pharmacognosy, 2(3), 127 (2015), DOI:10.13040/IJPSR.0975-8232.IJP.2(3).127-30.

40. S. Modi and B.D. Anderson, Molecular Pharmaceutics, 10(8), 3076(2013), DOI: 10.1021/mp400154a.

41. K. Hong, S. Sun, W. Tian, G.Q. Chen and W. Huang, Applied Microbiology and Biotechnology, 51(4), 523 (1999), DOI:10.1007/s002530051427.

42. K. Sivaram, M. C. Rao, G. Giridhar, M. Tejaswi, B. T. P. Madhav, V. G. K. M. Pisipati, and R. K. N. R. Manepalli, Rasayan Journal of Chemistry, 10(1), 697 (2017), DOI: 10.7324/RJC.2017.1011565

43. J. Coates, Encyclopedia of Analytical Chemistry,12, 10815(2000), DOI:10.1002/9780470027318.a5606.

44. P. Senthilkumar, S.S. Dawn, S. K. Samanvitha, S.S. Kumar, G.N. Kumar, and A.V.Samrot, Biocatalysis and Agricultural Biotechnology,12, 292 (2017), DOI:10.1016/j.bcab.2017.10.019.

45. R.A. Bini, D. A. Moraes and L. C. Varanda, British Journal of Pharmaceutical Research, 12(6), 1 (2016), DOI: $10.9734 / \mathrm{BJPR} / 2016 / 28070$

46. C.V. Nachiyar, A.B. Devi, S.K.R. Namasivayam and A. M. Rabel, Research Journal of Pharmaceutical, Biological and Chemical Sciences, 6(3), 116 (2015).

47. P. Sasikumar and P.M. Ayyasamy, International Journal of Current Microbiology and Applied Sciences, 4(12), 311 (2015).

48. F.V. Leimann, L.C. Filho, C. Sayer and P. H. H. Araújo, Brazilian Journal of Chemical Engineering, 30(2), 369 (2013), DOI:10.1590/S0104-66322013000200014.

49. E. Kilicay, E. Erdal, B. Hazer, M. Turk and E.K. Denkbas, Artificial Cells, Nanomedicine, and Biotechnology, 44(8), 1938 (2015), DOI:10.3109/21691401.2015.1115409

[RJC-4053/2018] 